\title{
Preparation of High-Resolution DTM and Orthophoto Using LiDAR in Nepal
}

\author{
Abhash Joshi, Sumeer Koirala \\ theabhash@gmail.com, mailtosumeer@gmail.com
}

\section{KEYWORDS}

Lidar; DTM; DEM; Orthophoto; Survey Department

\begin{abstract}
The high-resolution terrain model has varied usages including development planning, engineering works, environmental management, disaster management, urban planning, irrigation, geological study, archeological study and cadastral application. Currently, this data is not available for Nepal and it has also hindered the socio and economic development of the country.Airborne Lidar is economically cost-effective and viable means for topography related data collection.Lidar which is an acronym for Light Detection and Ranging is an active remote sensing technology in which Laser beams are used for surveying and mapping. The Survey Department of Nepal has taken initiative to prepare the High-Resolution DTM and Orthophoto of about 20,000 square kilometres of Nepal using Lidar surveying and mapping. Survey Department is conducting a LiDAR survey in the western terai regions of Nepal from Chitwan to Kanchanpur district. Airborne LiDAR survey data along with a very high resolution $(0.15 \mathrm{~m})$ orthophoto shall begenerated. Further, processing of LiDAR points data will generate a highly precise digital terrain model of $1 \mathrm{~m}$ grid data having an accuracy of $0.25 \mathrm{~m}$ and finally $0.5 \mathrm{~m}$ contour interval data.This endeavor is one of the milestones in the surveying and mapping sector of Nepal and it will have far-reaching consequence in the social and economic development of Nepal.
\end{abstract}

\section{INTRODUCTION}

Terrain Model and orthophoto provide a snapshot of our environment. High-Resolution Digital Terrain Model(DEM) and Orthophoto are the basis of many planning and decisionmaking works. Currently, high-resolution DEM and orthophoto for the whole of Nepal are not available. This has not only added a challenge in existing development work but also many development works are not started in the first place because of lack of data. Thus, the unavailability of this data has a high socio-economic cost for Nepal.

The need for high-resolution DEM for Nepal has been realized for a long time. The importance of high-resolution DTM and DEM for Nepal and its need to prepare different scale 
derived maps are highlighted in the Roadmap to Second-generation Reform in Land Governance of Nepal document (Ministry of Land Reform and Management, 2014). The post-disaster recovery framework has also emphasized the importance of high-resolution DTM and orthophoto for preparedness, recovery and rehabilitation from the disaster (National Reconstruction Authority, 2016).

Airborne Lidar is one of the most costefficient and effective methods for terrain data collection. Lidarstands for Light Detection and Ranging system is type of active remote sensing technology. It uses terrestrial, airborne and satellite-based platform to transmit laser light and receive reflected laser light to study the environment. It uses light in the form of a laser beam to measure ranges. In case of airborne LiDAR system light pulses are recored along with other flight and LiDAR sensor based data recorded at airborne system generate precise, three-dimensional information about the shape of the Earth and its surface characteristics (NOAA, 2018). This method has now become a standard norm to obtain DEM and DTM. It has special importance if the area is large and also if the topography is not uniform.

Traditional field surveying method can also be used to prepare high-resolution DEM. However,these methods are time-consuming and not cost-effective for the larger area. Further, this method does not work well in dense forest. Conventional surveying in Nepal mountainous terrains is not only time consuming, error-proneand expensive, it is almost impossible in many remote terrains. A well-calibrated Lidar system equipped with GNSS and Inertial Navigation System (INS) hasthe potential to provide highly accurate digital elevation data.(Filin \& Csatho, 1999). Its ability to provide $3 \mathrm{~d}$ coordinates directly in very coarse resolution makes it an appealing system.It can provide accurate and precise data from all parts of the terrain, remote or not. The accuracy of Lidar is similar to that of photogrammetry in many areas and even better in some area. (Xiaoye Liu, 2008). Lidar performs better than photogrammetry in a forest area with a dense canopy (Kraus \& Pfeifer, 1998)and also advantageous in the urban area as it is free from shadow.

Though Commercial application of airborne Lidar systems started in the mid-1990s (Pfeifer and Briese, 2007), Nepal has not used it on a large scale till now. There were few applications in a small scale of Airborne Lidar in private sectors for Hydropower survey, cable car survey and geological study only.

In Nepal, Survey Department is a national mapping agency and is responsible to prepare different base data. The department has prepared the topographical maps of the Lumbini zone through the assistance of JICA. Similarly, with the assistance of the Finland Government, topographical maps rest of the part of Nepalwas prepared. The whole country is covered by 706 sheets of 1:25,000 and 1:50,000 scale. The 1:25,000 data consist of contour at the interval of 20 meters and the data at the 1:50000 scale consists of contour at an interval of 40 meters.

The Survey Department of Nepal has now taken endeavour for Lidar Surveying and Mapping to generate high-resolution terrain models and orthophoto of whole Nepal.

The goal of the LiDAR surveying and mapping program is to generate High-Resolution DEM and Orthophoto Map with the application of Airborne Lidar surveying and Mapping. The major objectives of the program are:

- Prepare contour at an interval of 50 cm contour,

- Prepare Digital elevation model of resolution $1 \mathrm{~m}$

- Prepare a $15 \mathrm{~cm}$ GSD orthophoto map for the entire project area 


\section{WORKING AREA}

In this phase of the project, the working area consists of an approximately 20.000 square kilometre area of Terai, Siwalik and Mid hill region from Kanchanpur district to Chitawan district of Nepal. The area extends from79.9to 84.5 degree east longitude and 27.2 to 29.2 degree North latitude.

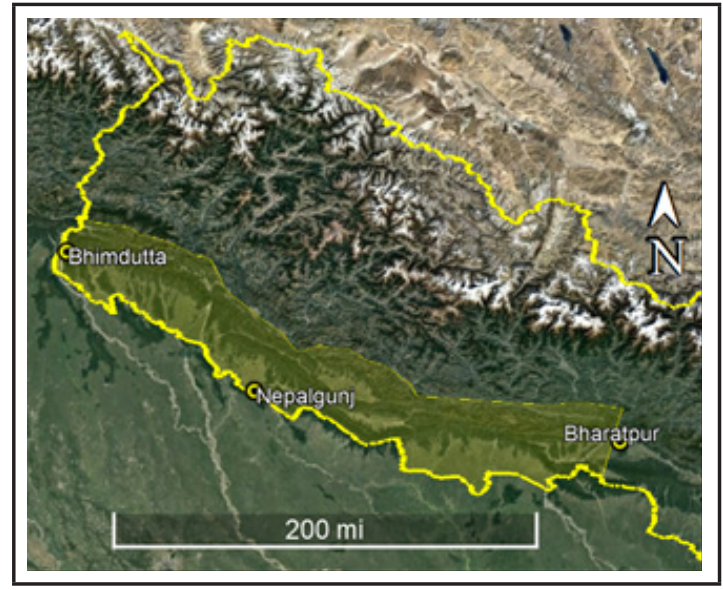

Figure 1 Project Area (Background Source: Google Earth)

\section{METHODOLOGY}

Lidar technology combines three separate technologies (lasers, the Global Positioning System (GPS), and inertial navigation systems (INS))into a single state of the art technology. The single narrow beam of the laser system is transmitted from the LIDAR system to the object, which reflected from the object is received by the receiver system in LiDAR. Travel time of the pulse from the LiDAR and back to the receiver is accurately measured. In LiDAR system range can be computed using the relation of speed of laser(equivalent to speed of light) and travelling time of the pulse. Computed range, laser scan angle, laser position based on GPS and laser orientation measured by INS computed precise location of the object on the ground surface.

To preparethe High-Resolution DTM and Orthophoto using Airborne Lidar technology following work shall be accomplished.

- Setting up of GNSS station monuments complying with IGS standard forgeodetic grade operation, covering entire project area. Construction of checkpoints covering the study area.

- Acquisition of Airborne Lidar data and producing classified and georeferenced point clouds from these data

- Acquisition of Orthophoto data using a 4 band RGB and IR (Near Infrared) cameraproviding a $15 \mathrm{~cm}$ GSD frames.

- Preparation of Digital Surface Model and Digital Terrain Model of $1 \mathrm{~m}$ resolution, and topographic contour with $0.5 \mathrm{~m}$ contour interval.

- Setting up a Data Processing Lab with all required hardware and software installed.

To accomplish the above-mentioned work the project work is divided into the following steps. Until the date of this writing, aerial data acquisition is being conducted.

\section{FLIGHT PLANNING}

Planning the flight is one of the major initial tasks for the Lidar survey. The type of aircraft to be used, topography, number of points per square meter and flight paths based on them should be determined during the flight planning phase. In this project entire coverage area is subdivided into three major zones: Zone-1, Zone-2 and Zone-3 and each zone is subdivided into operational areas. One base is selected in each zone for flight operation. Flying Operations in Zone-1 is based at Bhairahawa (VNBW) airport,flying Operations in Zone-2 is based at Nepalgung (VNNG) airport and flying Operations in Zone-3 is based at Dhangahdi (VNDH) airport. LiDAR flight plan should maintain forward overlap (forelap) between successive exposures in each run minimum of 15 percentage. Also, the lateral overlap (sidelap) between adjacent strips should be a minimum of 15 percentage. 


\section{GNSS STATION AND CHECKPOINTS ESTABLISHMENT}

Primary control network consisting of 46 IGS grade GNSS monuments referenced to the geodetic control network are established covering the whole project area. The spatial location of the stations is selected in such a way that the aircraft remains inthe $15 \mathrm{~km}$ maximum range from any of these base stations at all time during flight operation. These CORS GNSS monuments serve as base stations during the flying operation.

The GNSS system on-board aircraft will use these base station data for estimating accurate and precise positions of the aircraft at each instant of time. The aircraft positioning accuracy is linked to the absolute positional accuracy of the Lidar points on the ground. So, these 46 DGPS stations are important for the ultimate accuracy of the final Lidar deliverables. These stations are the Datum station for the project and all the positional accuracy of entire project deliverables are linked to these 46 stations.

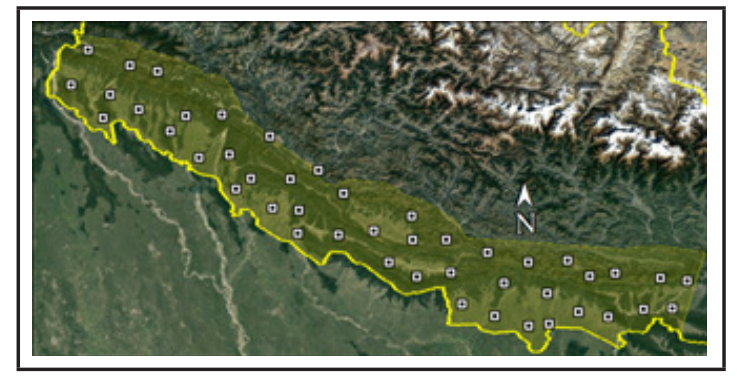

Figure 2.Distribution of GNSS points in the project area

Also, 400 checkpoints are established in the study area which is used for orthophoto generation and for ensuring the accuracy of the Lidar data.

\section{AERIAL FLIGHT}

Airborne LiDAR and photogrammetry data acquisition should becarried in the season when vegetation coverage is minimum, clear sky isavailable, the ground is not covered with floodwater or harvested vegetation, and ground fog andmist are absent. The best season is thus theMarch-June period, immediately after the winter and before the monsoon clouds arrive. Aerial flight for the project will be conducted until June before the arrival of Monsoon.

LiDAR sensor collects the returned pulse after reflection. During the LiDAR flight, LiDAR sensor sends the laser beam to the ground surface in the form of mass points, the first return of LiDAR mass points generates digital surface model whereas DTM is generated from the LiDAR mass point data which is classified as "Ground".

The data was archived on daily basis to alocal computer before archiving to Data Centre inside the Survey department premises. Data processing will be carried out at the data centre in Kathmandu.

\section{DATA PROCESSING}

Lidar data and photogrammetric data will be processed at the Data centre of the Survey Department. Data processing will be also a big challenge because of the large volume of data. High performance computation techniques using GPU and multiple CPU shall be used for processing. Terrasolid software shall be used for orthorectification and Lidar data processing.

\section{OUTPUT}

The major outputof the study can be summarized as follows.

- Raw LiDAR (point cloud) survey data comprising all returns $\left(1^{\text {st }}, 2^{\text {nd }}\right.$, etc..., and last return), representing all ground and nonground returns and including overlapping swathes. LiDAR Point Density shall be 9-14 points/square meter.

- Digital Surface Model and Digital Terrain Model of $1 \mathrm{~m}$ grid resolution. Fundamental vertical accuracy: Root Mean Square Error $<=+/-.25 \mathrm{~m}$. or better on the clear or vegetated ground. 
- The contour of $0.5 \mathrm{~m}$ interval

- Near-natural colour-balanced digital photographyfor photogrammetry application.

- Orthorectified multispectral digital photograph with $15 \mathrm{~cm}$ GSD. Fundamental horizontal accuracy of orthophoto should be $<=+/-.10 \mathrm{~m}$.

- Colour balanced mosaic with15 cm GSD

- A report containingthe location and description of all GNSS stations.

\section{SPATIAL DATA VALIDATION}

The fundamental vertical accuracy of the point cloud dataset will be determined with checkpoints located only in open, relatively flat terrain, where there is a very high probability that the sensor will have detected the ground surface. The vertical accuracy of the point cloud dataset will be tested using a TIN surface constructed from bare-earth LiDAR points compared against ground survey checkpoints. The number of checkpoints (locations) is dependent on the extent of the survey. A minimum of 20 checkpoints (locations), then 1 point per $50 \mathrm{~km}^{2}$ in $7 \mathrm{~km} * 7 \mathrm{~km}$ grid in different vegetation types with 95 percent confidence interval.

\section{BENEFITS}

Lidar data will have varied application in development work, planning and spatially enabled decision making. The data can be used for monitoring and studying landslides all over Nepal. Flood modelling, flood-disaster planning and developing flood early warning system needsDEM which comes from this Lidar project.Lidar data is essential not only during the planning and construction phase of road and railways but also in Improving the resilience of the infrastructures(Soilán et al., 2019).Similarly, this data can also be used for the archeological study. Lidar imagery is a powerful tool for an archeological study especially in thearea covered with trees and vegetation because of its penetrating capacity
(Chase et al., 2011). The raw data will have immense scientific value in different research works such as earthquake monitoring, climate change studies, vegetation monitoring, glacial study etc. Finally, the data can be used to make the cadastral maps also.

\section{CONCLUSION}

Lidar is a state of the art technology that has revolutionised how terrain data are collected.This visionary initiative from the Survey Department will have a far-reaching consequence on economic and social development in Nepal. The relative speed at which it can be used to collect, analyses and prepare digital elevation model data, compared to any other technology, will support the Survey Department to meet the demand for accurate survey datasets in a timely fashion. LIDAR can greatly reduce survey time and effort in areas where This translates directly into cost savings. The methodology adopted in this project is the best practice adopted in this field. The methodology should evolvewith the development of new technologies.

LiDAR surveying and mapping program has also been categorized as a game-changer project by the National Planning Commission's annual development programme for fiscal year 2077/78. The Survey department will also begin LiDAR surveying and mapping in eastern terai region of Nepal(from Chitwan to Jhapa District) in collaboration with JICA in fiscal year 2077/78. The Survey Department is planning to conduct LiDAR all over the country in near future.

\section{REFERENCES}

Chase, A. F., Chase, D. Z., Weishampel, J. F., Drake, J. B., Shrestha, R. L., Slatton, K. C., Awe, J. J., \& Carter, W. E. (2011). Airborne LiDAR, Archaeology, and the Ancient Maya Landscape at Caracol, Belize. Journal of Archaeological Science, 38(2), 387-398. https://doi. org/10.1016/j.jas.2010.09.018 
Filin, S., \& Csatho, B. (1999). A Novel Approach for Calibrating Satellite Laser Altimeter Systems. International Archives of Photogrammetry and Remote Sensing, 32(3W14), 47-54.

Kraus, K., \& Pfeifer, N. (1998). Determination of Terrain Models in Wooded Areas with Airborne Laser Scanner Data. ISPRS Journal of Photogrammetry and Remote Sensing, 53(4), 193-203.

Ministry of Land Reform and Manangement. (2014). Roadmap to Second Generation Reform in Land Governance of Nepal. www.molcpa.gov.np
National Reconstruction Authority. (2016). Post Disaster Recovery Framework.

Soilán, Sánchez-Rodríguez, Río-Barral, PerezCollazo, Arias, \& Riveiro. (2019). Review of Laser Scanning Technologies and Their Applications for Road and Railway Infrastructure Monitoring. Infrastructures, 4(4), 58. https://doi. org/10.3390/infrastructures4040058

Xiaoye Liu. (2008). Airborne LiDAR for DEM generation: Some critical issues. Progress in Physical Geography: Earth and Environment, 32(1), 31-49. https:// doi.org/10.1177/0309133308089496

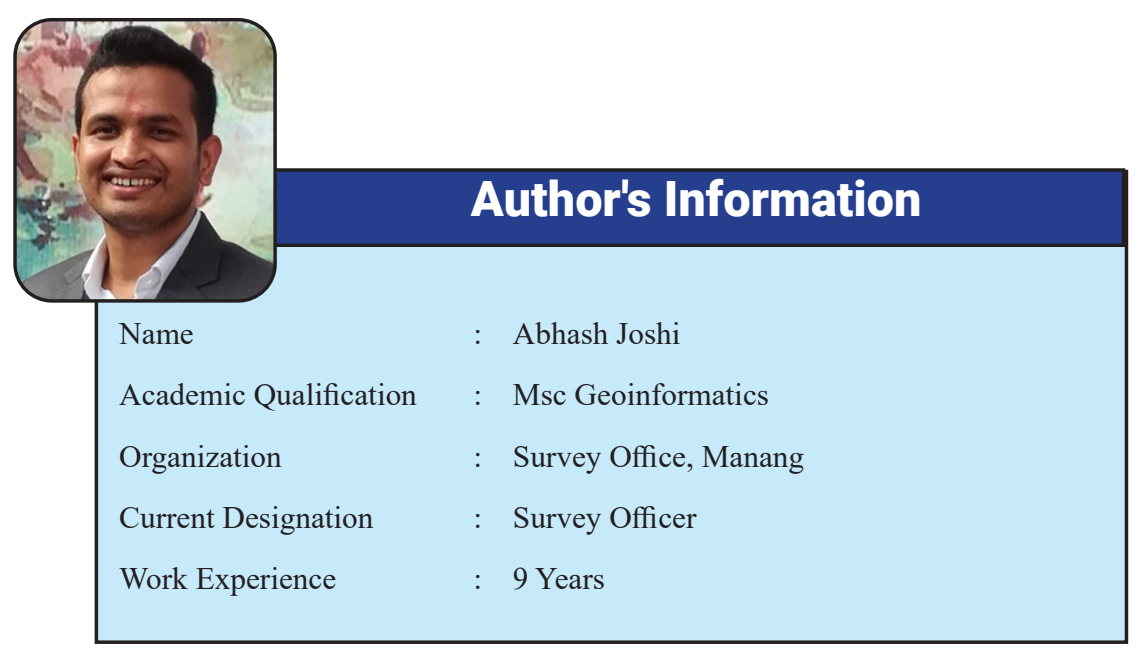

